\title{
Comportamentos de Saúde e Doença numa Comunidade Cabo-Verdiana em Lisboa'
}

\section{Health and Illness Behaviors in a Cape Verdean Community in Lisbon}

\author{
Bárbara Bäckström \\ Doutora em Saúde Internacional. Professora Auxiliar do Depar- \\ tamento de Ciências Sociais e de Gestão da Universidade Aberta, \\ Investigadora do Centro de Estudos das Migrações e das Relações \\ Interculturais (Cemri) - Universidade Aberta. \\ Endereço: Rua da Escola Politécnica 147, 1200 Lisboa, Portugal. \\ E-mail: barbarab®univ-ab.pt \\ I Esta pesquisa teve financiamento parcial da Fundação para a \\ Ciência e Tecnologia de Portugal - bolsa de doutoramento.
}

Resumo

O objetivo foi compreender como os indivíduos se comportam em termos de saúde e o que fazem em caso de doença. Análise comparativa realçou semelhanças e divergências de práticas de saúde ou em caso de doença. 0 estudo foi efetuado numa amostra de 40 cabo-verdianos da primeira geração residentes na região de Lisboa, dividida em subgrupos: grupo social, geração e genero. Baseou-se em metodologia qualitativa com entrevistas semi-estruturadas. As práticas analisadas foram agrupadas em preventivas e de saúde, práticas utilizadas em episódios de doença, recursos para prevenção e tratamento, utilização de remédios caseiros e outros recursos ou terapeutas. Indivíduos experimentaram, ao nível das práticas, três sistemas de saúde que coexistiam em Cabo Verde, oficial, popular e tradicional e o recurso à religião. 0 discurso acerca das práticas de saúde e de doença demonstrou existirem diferenças, em alguns aspectos, entre grupos sociais e entre generos e gerações. Práticas de saúde destes imigrantes são idênticas às dos portugueses em contextos socioeconomicos semelhantes. Resultados sugerem existência de diferenças entre grupos sociais relativamente às práticas, na esfera da saúde e da doença. Mais que cultura e etnicidade, que se moldam às condições materiais de existência, neste estudo, o nível socioeconomico determinou as maiores diferenças a interferir nas práticas de saúde e doença, de grupo com cultura de base comum. Em geral, os indivíduos sobrevalorizaram sua identidade étnica e cultura de origem. Pertencimento a grupos sociais diferentes dá origem a partilha do sentimento de pertença cultural, mas não a comportamentos e práticas idênticos.

Palavras-chave: Práticas de Saúde; Utilização dos serviços de saúde; Condições socioeconômicas; Imigrantes. 


\section{Abstract}

This study aims at analysing, through personal reports, the way individuals behave in terms of health and illness. A comparative analysis of the collected data was performed, with the purpose of highlighting divergences in the health and illness practices. The study was undertaken with a sample of 40 «first generation» Cape Verdeans living in the Metropolitan area of Lisbon, divided into distinct groups: social (popular and elite), generation (younger and older) and gender (men and women). A qualitative methodology was employed, by conducting semi-structured interviews for the collection of information. The health and illness practices were grouped into preventive and health care practices, practices used in episodes of illness, resources used for prevention and treatment, use of home remedies, and other alternative resources. Individuals who are part of our study experimented, at the level of practices, with the three health systems that existed in Cape Verde, namely, the official, popular and traditional, and recourse to religion. The discourse analysis concerning health and disease practices showed there are differences, in some respects, between social groups. There were also slight differences between genders and generations. These immigrants' health practices are identical to those of the Portuguese who are in similar socioeconomic contexts, with no significant effects of immigration itself on these practices. The analysis of the results confirms the existence of differences between social groups concerning the health and illness practices. They were more determined by the socioeconomic factors than by the cultural and ethnic aspects. Those differences also highlighted the existence of a unifying aspect, resulting from their cultural heritage. Although belonging to different social groups, the existence of a common culture and ethnic identity originates a shared feeling of cultural belonging, but not identical behaviours and practices.

Keywords: Health Practices; Use of Health Care Services; Socioeconomic Status; Immigrants.

\section{Introdução}

Este artigo analisa práticas de saúde e de doença numa comunidade imigrante residente na área Metropolitana de Lisboa. Foi feita uma análise comparativa dos dados recolhidos de forma a fazer sobressair as divergências das práticas de saúde e de doença dos entrevistados e perceber se as diferenças se deviam a fatores socioeconomicos, a fatores culturais e de identidade étnica, ou à combinação de ambos. Partimos do pressuposto que os imigrantes têm perfis distintos, entre eles, no que se refere às práticas de saúde e de doença, consoante o grupo social, a geração e o genero. Segundo o que é apontado por Sundquist (Sundquist, 1995, p. 777-787), as condições sociais e as atitudes e hábitos culturais de um determinado grupo podem estar estreitamente associados às suas práticas de saúde. A saúde dos imigrantes inscreve-se num quadro particular onde interfere o caráter cultural da pertença étnica. No entanto, a saúde pode variar consoante os alvos e os contextos de comparação social e economica. 0 artigo pretende ilustrar e descrever as múltiplas práticas existentes em contexto migratório, bem como a utilização dos serviços de saúde.

\section{Métodos}

Selecionou-se uma amostra intencional de 40 indivíduos cabo-verdianos da chamada "primeira geração" de imigrantes, residentes na região de Lisboa, a qual para efeitos de análise foi dividida em dois grupos socioeconomicos selecionados a partir da escolaridade, profissão e rendimento familiar aos quais se deu a denominação "grupo popular" e "grupo de elite”. Fez-se também uma análise por geração (mais jovens e mais velhos) e genero (homens e mulheres). Cada um destes grupos é composto por 20 indivíduos. O critério essencial de inclusão dos elementos na amostra assentou na exigência de todos eles terem nascido em Cabo Verde e lá terem vivido até aos 17 anos inclusive. Optou-se por uma metodologia qualitativa através da realização de entrevistas semiestruturadas para recolha da informação.

Os instrumentos de trabalho selecionados consistiram nas entrevistas semi-estruturadas realizadas a todos os indivíduos que constituem a amostra através de gravação áudio de cada entrevista in- 
dividual, após contatos prévios efetuados com os informantes privilegiados, bem como o contato com as associações ligadas à comunidade cabo-verdiana, tanto em nível central, em Lisboa, como com associações sediadas nos bairros de maior concentração desta população.

O tratamento dos dados consistiu na análise de conteúdo temático das entrevistas e na identificação de diferenças e semelhanças entre e intra cada um dos subgrupos. A análise dos dados centrou-se numa análise de conteúdo, qualitativa, em que ao longo dos relatos, se pretendeu encontrar ideias recorrentes, de forma a perceber as tendências e a agrupá-las, se fosse caso, em função dos grupos a que pertenciam os indivíduos. Esta análise permitiria estabelecer senão tipologias, pelo menos padrões de comportamento "típicos", consoante os grupos, quer ao nível das representações, quer ao nível das práticas (Bardin, 2007). A análise de conteúdo aqui estabelecida foi feita através de uma leitura qualitativa dos dados e é uma análise tipológica (Guerra, 2006). Procuramos descobrir categorias de temas, as tendências de resposta de maior frequência e padrões de resposta onde existissem coincidências e divergências e tentamos perceber a quem pertenciam estes padrões e fundamentalmente de que dependiam os mesmos para construir um sistema ou um conjunto de relações entre essas classes de respostas e as características sociais, de genero e de geração dos entrevistados.

Foi necessária a redução dos dados através de processos de seleção, focagem, simplificação, abstração e de transposição do material recolhido, bem como a anotação das regularidades, os encadeamentos e as propostas de interpretação. Procedemos a uma apresentação e organização dos dados para fins comparativos, através das grandes linhas de coincidências e de discordâncias.

\section{Resultados e Discussão}

Para o Cabo-Verdiano, a doença é a totalidade que faz com que o indivíduo seja visto como um todo, na sua vivência social e cultural, onde os elementos biológicos, psíquicos e emocionais estão assentes num referencial cultural e social que lhe dá a sua visão cosmológica como indivíduo. Entre a população cabo-verdiana é utilizado o conceito de remédio de terra e não o de medicina popular. 0 remédio está ligado à cura, e envolve tudo o que tenha a ver com a prevenção e diagnóstico da doença e da sua cura, desde os elementos utilizados para esse fim até aos agentes que fazem o diagnóstico e a cura. A literatura que aborda a medicina popular ${ }^{2}$ em Cabo Verde faculta-nos referências sobre o recurso a produtos naturais e culturais como plantas e minerais ou rituais de diagnóstico e cura, manipulados pelo curandeiro ou pela própria clientela na cura doméstica, segundo hábitos culturais próprios transmitidos através da tradição oral e utilizados não individualmente, mas fazendo parte de um conjunto e quotidiano importante para a sobrevivência do grupo, o seu equilíbrio físico, espiritual e social» (Rodrigues, 1991). Existe um fenomeno específico dentro da religião, o chamado movimento espírita, do Racionalismo Cristão, sobretudo na ilha de São Vicente, predominante no seio da elite intelectual. Têm centros espíritas onde se recorre para sessões públicas de limpeza psíquica (Vasconcelos, 2001), sendo que a incorporação de espíritos pelos médiuns (chamada de "manifestação"), produz frequentemente diagnósticos espirituais, nos quais são revelados feitiços, maus-olhados ou a influência dos "espíritos inferiores”. Para além do racionalismo cristão, as igrejas pentecostais, como é o caso da IURD, têm vindo a revelar a sua imposição. Em Cabo Verde o remédio da terra e a medicina oficial coexistem no mesmo espaço social, com plena aceitação por parte da população, apesar da necessária adaptação de novas técnicas e novos valores que são introduzidos pelo progresso médico da medicina dita "moderna". Em Portugal, as práticas são mais parecidas com as dos Portugueses e coincidem com a maioria das práticas dos indivíduos do país de acolhimento. Conforme já referido, os imigrantes trazem com eles sistemas de crenças e práticas de saúde dos seus países com heranças e experiências culturais próprias, podendo manter-se ativas por vezes durante várias gerações. Todos os recursos a que se recorre no tratamento e cura são produto de cultu-

2 Popular aqui refe-se a práticas familiares e caseiras exercidas pela comunidade 
ras e correspondem a práticas preventivas e ações terapêuticas comuns nas tradições culturais. $\mathrm{O}$ uso simultâneo das medicinas tradicional e "moderna" coexiste e um sistema não substitui o outro. Partimos da ideia de que não existe uma correlação direta entre uma utilização continuada do sistema tradicional e o nível de utilização dos serviços modernos, nem uma correlação com um nível mais elevado de aculturação na cultura de acolhimento. A flora tem um papel fundamental enquanto recurso médico e que se explica pela sua situação geográfica isolada. As plantas são usadas sob a forma de infusões ou xaropes. Esta prática encontra-se ainda viva junto dos mais velhos e nos curandeiros ou "endireitas". É verdade que o sistema sanitário ocidental sobrepôsse parcialmente e conseguiu fazer recuar a medicina tradicional, sem, no entanto, extingui-la. A medicina mais popular tornou-se numa questão de sobrevivência. A medicina tradicional ${ }^{3}$ é praticada pelos "curandeiros" e sob a forma de medicina popular "doméstica" comum, em que o saber se transmite no interior das famílias.

Todas as pessoas entrevistadas viveram pelo menos até aos 17 anos de idade em Cabo Verde. Já na altura em que lá viviam procuravam o médico em caso de doença, e iam às consultas no posto de saúde ou no hospital. Mas, quase todas, com raras excepções, relatam episódios que ocorreram desde o nascimento até ao fim da adolescência, em que os tratamentos eram feitos em casa, os quais são conhecidos pelo nome de remédios de casa ou remédios de terra 4 .

Em termos de práticas de saúde concretizadas em Portugal, os profissionais de saúde portugueses alertam para o fato do comportamento e das práticas de saúde dos imigrantes, assim como o uso dos serviços de saúde terem um forte impacto no seu estado de saúde. Segundo Fonseca (2009) são raros os estudos sobre as diferenças no acesso dos vários grupos de imigrantes residentes em Portugal aos cuidados de saúde. Contudo, informações parcelares sobre o uso dos diversos serviços indicam algumas diferenças entre as comunidades de imigrantes. Os imigrantes dos PALOP são os que menos utilizam os serviços de saúde, quer preventivos, quer curativos, mas em contrapartida usam mais que outras comunidades os centros de saúde e hospitais. A explicação tem a ver com o tempo de residência em Portugal em comparação com as restantes comunidades. Além disso, alguns vêm receber tratamento em Portugal ao abrigo dos acordos de cooperação no domínio da saúde celebrados entre Portugal e os PALOP (Bäckström 2009b). Em relação às práticas de saúde dos imigrantes, sabe-se ainda que, por vezes, o recurso à consulta materno-infantil é uma das vias, porque é gratuita, usada como "porta de entrada" para aceder a outro tipo de cuidados e serviços médicos. As questões culturais e identitárias desempenham um papel central no estado de saúde dos imigrantes e no uso dos serviços de saúde. O uso da medicina popular e a consulta de curandeiros é uma prática recorrente em alguns segmentos da população residente em Portugal (Sousa, 2006; Manuel, 2007; Monteiro, 2007). As razões apontadas para este comportamento entre os imigrantes prendem se com: falta de confiança no SNS; receio de serem presos ou repatriados devido a situações de irregularidade quanto ao estatuto legal; desvalorização dos problemas de saúde; fuga aos estigmas e estereótipos relacionados com determinados problemas de saúde (ex. HIV-SIDA; doenças mentais); e desconhecimento da existência de determinados serviços (ex. consultas materno-infantis gratuitas; consultas de planejamento familiar).

A construção social da saúde, a doença e a etnicidade não podem ser isolados dos efeitos de estatuto social dos imigrantes, do genero e da idade (Germov, 1998). Pelo contrário, a etnicidade interage com cada um destes fatores. Muitos estudos chegam à mesma conclusão, afirmando que a saúde dos imigrantes recém-chegados é melhor do que a dos indivíduos "locais". Os níveis de morbidade para os

\footnotetext{
3 A Medicina tradicional inclui os curandeiros

4 Em Cabo Verde a medicina popular é apelidada de "Remédio da Terra". Nas nossas entrevistas encontrámos várias expressões para este termo: no caso dos remédios, temos termos como uma palha, ervas, medicina tradicional, medicamento da terra, produtos de ervanário, remédios naturais ou ainda remédios de casa; no caso dos terapeutas, encontramos esperta, pessoa tradicional, farmacêutico, curandeiro, parteira e curioso.
} 
imigrantes tendem a ser mais baixos do que para a população de origem. Ao imigrarem, as pessoas são "selecionadas" com base no seu estado de saúde. À medida que o tempo de residência aumenta, verificase que aumentam também as taxas de morbidade e de mortalidade dos imigrantes, como consequência dos estilos de vida, particularmente do regime alimentar. As desordens psicológicas e as depressões atingem certos grupos dentro de imigrantes, para o que contribuem as dificuldades no emprego e no alojamento, acumuladas a uma mobilidade social e espacial, à separação da família e a problemas de comunicação, bem como ao confronto com sentimentos de racismo e de discriminação. As determinantes da relação entre grupos de imigrantes, grupos étnicos e saúde são geralmente compostas por fatores de pertença a um grupo, fatores socioculturais e fatores socioeconómicos (Venema, 1995). A pertença a um grupo tem em conta a discriminação social, economica e étnica, a língua, a separação das famílias e as experiências antes e durante a migração. 0 fator sociocultural evidencia as diferenças de cultura e o socioeconomico inclui a posição social, o acesso ao consumo de bens, a participação no mercado de trabalho, valores e normas e o acesso à informação. As doenças, quando consideradas pelos próprios, parecem ser referidas enquanto problemas e parecem por vezes derivar de práticas culturais (Donovan, 1984, p. 663-670).

Existe uma diferença no que entendemos serem práticas de saúde e comportamentos de doença. Os primeiros integram atividades que surgem na relação com a manutenção da saúde, enquanto os segundos são respostas que surgem na consequência de sintomas de doença. No caso deste estudo, quer as práticas de saúde, quer os comportamentos de doença, baseiam-se em discursos sobre as práticas e não à sua observação. Tentamos compreender o sentido que as pessoas dão às suas práticas e como pensam, como falam ou como discursam sobre a relação entre saúde e doença. 0 discurso poderá não corresponder tanto à realidade das práticas, mas, sobretudo, a uma imagem que se quer dar 'ao outro', a imagem que se entende como a que deveria ser a desejável sob o ponto de vista dos outros. As experiências passadas vão condicionar as atitudes presentes, que por sua vez vão atuar sobre o comportamento. Há também que distinguir duas categorias de práticas. Uma primeira relacionada com práticas quotidianas que podem por em causa a saúde. Trata-se de práticas indiretamente ligadas à saúde - tendo uma relação de "causa - efeito", associadas aos estilos de vida, tais como hábitos alimentares, consumo de álcool ou tabaco, exercício físico, ocupação de tempos livres, que correspondem a comportamentos mais ou menos saudáveis. Uma segunda categoria de práticas, reúne as práticas de saúde propriamente ditas, sejam as práticas preventivas e curativas que passam pelas consultas de rotina, pelos tratamentos, diagnósticos, exames e a própria utilização dos serviços de saúde.

\section{Práticas Preventivas}

De um modo geral, os indivíduos consideram a prevenção importante para manter uma boa saúde e para estar em forma, sobretudo no caso das mulheres com filhos. Há discursos que frisam a importância das medidas de prevenção com o intuito de saber exatamente o que se passa ao nível da saúde. Este discurso foi constante no grupo de elite enquanto no grupo popular refere-se mais às idas ao médico sempre que algo não está bem, a aquisição de medicamentos. Pelo contrário, no grupo de elite faz-se a alusão ao fato de manter o hábito de fazer análises e check-ups de rotina como forma de prevenção. É necessário distinguir as idas ao médico, ou melhor, o recurso aos serviços de saúde, como medida preventiva, evocado pela elite e o recurso que se prende com o sofrimento de uma sintomatologia patológica e o pedido de medicamentos, referido, sobretudo, pelo grupo popular. Há ainda, neste grupo, particularmente entre os "mais velhos" quem atribua a sua boa forma física aos cuidados que tem com a saúde e a práticas de conservação de estilos de vida consideradas saudáveis (associadas a não ter comportamentos nocivos para a saúde como beber, fumar, regime alimentar, exercício físico...) e a levar uma vida regrada. Grande parte dos elementos do grupo de elite pertencente à geração dos "mais velhos" refere ter uma preocupação com a alimentação, evitar gorduras, fritos e açucares e praticar uma alimentação mais à base de grelhados, cozidos e vegetais. Por sua vez, estes são também 
quem afirmam tomar um pequeno-almoço completo, porque consideram esta a refeição mais importante do dia. Entre as pessoas mais jovens há quem diga preocupar-se bastante em termos de alimentação, não ingerindo muitas gorduras e comendo a horas certas. No caso dos mais velhos, alguns indivíduos dizem que têm muito cuidado com a alimentação. Em termos de genero, verifica-se que são mais as mulheres a afirmar que têm cuidados com a alimentação e que, por vezes, têm de seguir uma dieta adequada ao seu problema de saúde. Também encontramos mais mulheres do que homens que referem que têm muitos cuidados alimentares no sentido de fazerem uma alimentação racional e saudável.

Alguns homens afirmam com um certo "orgulho" que comem de tudo ou "comemos tudo, Graças a Deus" em tom de afirmação da sorte ou possibilidade que têm de, por um lado, não terem nenhum impedimento de saúde que os condicione em termos alimentares, e, por outro, querendo realçar que não têm dificuldades financeiras para adquirir os alimentos, aparentando, no entanto, não ter a noção de que comer de tudo nem sempre é o mais saudável. Embora exista um maior número de homens do que mulheres que reconhecem a importância das práticas de prevenção, afirmando que deveriam ir regularmente ao médico, estes acabam por admitir que há já muito tempo que estão para o fazer. Estamos aqui perante um exemplo de como as representações podem contradizer as práticas.

Quanto à geração, alguns jovens manifestam consciência dos perigos de hábitos nocivos e referem que tentam ter cuidado com o álcool e com o tabaco.

Encontrámos relatos que mencionam que alguns homens passaram a beber mais depois de chegaram a Portugal, expressos apenas por indivíduos do sexo masculino, do grupo popular: "Devia beber com um bocadinho de cautela, não é? Há meses em que é todos os dias, chego a um café e bebo, todos os dias...Devia deixar o ambiente dos cafés" $\{\mathrm{H}, \mathrm{MJ}, \mathrm{GP}\}$; “Anda no psicólogo porque andava a beber, bebia, tinha problemas com a mulher...tinha descontrolo com a mulher, ela tinha outro homem...eu passei a uma classe de bêbado... chamavam-me bêbado" $\{\mathrm{H}, \mathrm{MV}, \mathrm{GP}\}$. Não captamos discursos sobre o consumo de álcool nas mulheres, por este ser um comportamento que em geral é mal aceito. Talvez por esta razão, não tenha sido possível captar mais dados no grupo de elite e no grupo das mulheres, independentemente do seu grupo social. Não encontrámos nas entrevistas referências relativamente ao alcoolismo, ou porque os entrevistados “escondiam" esse comportamento, ou ainda porque provavelmente não percebem esses comportamentos como alcoólicos, visto que a bebida é um hábito que faz parte da cultura cabo-verdiana.

A predominância de alguns hábitos perigosos para a saúde, entre os elementos do grupo popular, permite-nos ir ao encontro da afirmação de Nettleton quando diz que "Ao nível da saúde, os comportamentos mais arriscados como fumar, consumo de álcool, dietas inadequadas, estão associados a menos educação e circunstâncias de vida mais pobres» (Nettleton, 1995). Um hábito que parece ser muito comum a todos os cabo-verdianos, sobretudo, no tempo em que ainda viviam em Cabo Verde, sendo muito poucos os que o abandonaram, é a prática de atividades desportivas, sobretudo no caso dos indivíduos mais velhos. O hábito de prática atual de exercício físico é referido por muitos inquiridos, sobretudo pelos indivíduos do grupo de elite, que referem que fazem ginástica de manutenção em casa. No entanto, muitos dos inquiridos referem que em Cabo Verde praticavam mais exercício do que em Portugal.

Quanto à diferenciação por genero, verifica-se que este tem uma certa interferência em algumas respostas dadas por mulheres do grupo popular, quando dizem não ter tempos livres, já que esse tempo é utilizado para tratar da casa ou porque simplesmente não têm atividades fora de casa: "Às vezes, quando está o tempo bom, levo o miúdo para passear... e passo o resto em casa, a tratar da roupa" $\{\mathrm{M}, \mathrm{MJ}, \mathrm{GP}\} ;$ " $E u$ não tenho tempo no fim-de-semana, sempre em casa, arrumar casa, passo ferro...” (M, MJ, GP\}; "Fim-de-semana, ao sábado trabalho e ao domingo em casa, não vou a lado nenhum" $\{\mathrm{M}, \mathrm{MV}, \mathrm{GP}\} ;$;"Tempo livre, não há. Tratar da casa, vou arrumar, lavar... os meus filhos não está, eu tenho que tratar da casa” $\{\mathrm{M}$, MV, GP\}. Predominantes no grupo de elite, em ambas as gerações, mas mais referidos por mulheres, são a leitura e idas ao cinema. 


\section{Recursos Utilizados em Episódios Concretos de Doença}

Um dos temas principais de conversa, quando se fala acerca da saúde, é o assunto das doenças. Não se encontram grandes disparidades face aos episódios de doença, a não ser o fato de aparecerem mais queixas por parte dos indivíduos do grupo popular e de existirem doenças próprias das mulheres. Talvez se possa também registrar que quatro episódios atuais de doenças de ordem psicossomática (ansiedade, dores de cabeça, enxaquecas, insonia) são mencionados por pessoas do grupo de elite, enquanto no grupo popular não se registraram queixas deste tipo. Algumas doenças estão relacionadas com o contexto socioeconomico e o local onde as pessoas residem no momento da entrevista. Dos diferentes tipos de queixas enumeradas, ou sejam, as doenças de que as pessoas se queixam, quase todos os casos correntes são cronicos ou frequentemente reincidentes e exigem tratamentos e cuidados prolongados. Os casos crónicos mais evidentes são os três doentes com insuficiência renal que estão completamente dependentes de um tratamento continuado. Outras situações que também podem ser consideradas cronicas, já que estão sempre presentes na vida das pessoas e exigem uma vigilância permanente são, entre outras, diabetes, hipertensão, coração, colesterol, brônquios, problemas de coluna e reumatismo. Existem, no entanto, situações pontuais que estavam latentes na altura da realização da entrevista: "estou com corrimento no peito...", "Eu ando com problema de ouvidos"; "Estou com a garganta atingida"; "Estou com gripe". Outros episódios relatados com maior frequência, e que tiveram lugar anteriormente, foram gripes, apendicites, quistos e intoxicações alimentares.

Podem-se identificar doenças ou episódios específicos em cada um dos grupos sociais (por exemplo, acidentes de trabalho, no grupo popular, ou uma depressão nervosa e ansiedade no grupo de elite), o que, no entanto, não nos permite retirar conclusões de carácter geral nem permite estabelecer diferenças muito acentuadas. Também não se detectaram diferenças entre os grupos, quando são referidas as doenças que sofreram enquanto viviam em Cabo Verde. A maior parte dos relatos reporta-se às doenças que tiveram durante a infância. As mais mencionadas foram o sarampo, varicela, constipações e gripes, febre tifóide e febre intestinal. Foram também referidos casos de bronquite asmática, alergias, pneumonia, dores de cabeça, paludismo, operação a um caroço, quisto e uma intoxicação alimentar.

Nesta temática, existem doenças que pensamos estarem relacionadas com o contexto geográfico e climático próprio de Cabo Verde. Uma doença que aí existia e foi erradicada era o paludismo. As alergias, bronquite asmática, broncopneumonia, pneumonia e asma também podem estar relacionadas com o clima e as alergias, dores de cabeça, com o tão falado vento alísio ou o vento que vem do Saara. A febre tifóide e a febre intestinal também estão relacionadas com o contexto geográfico, a época e o clima e as águas.

Em termos de gerações, verifica-se que o número de episódios atuais de doença está repartido de modo quase equivalente entre os dois grupos. Consideramos que o tipo de doenças ou problemas relatados são próprios e específicos de cada um dos grandes grupos etários. Existem doenças comuns às duas gerações, mas, como se pode verificar, os problemas de saúde mais específicos do grupo etário "mais velhos” são provocados por diabetes, pela hipertensão arterial, pelo coração, entre outros.

Ao procurarmos saber como as pessoas procederiam, caso estivessem em Cabo Verde com o atual problema de saúde relatado, a maioria faria exatamente a mesma coisa, isto é, iria procurar um médico: "Eu também seguiria os conselhos do médico" $\{\mathrm{H}, \mathrm{MV}, \mathrm{GE}\} ;$ " Atualmente acho que era relativamente fácil tratar, porque éassim, já há gastrenterologistas que fazem endoscopias" $(\mathrm{H}, \mathrm{MJ}, \mathrm{GE}\}$; “Fazia na mesma. Tudo igual" $\{\mathrm{M}, \mathrm{MV}, \mathrm{GP}\} ;$ "Ia para um médico para ver o que é para fazer" $\{\mathrm{H}, \mathrm{MJ}, \mathrm{GP}\}$. Nos casos em que as pessoas afirmaram que procurariam remédios caseiros, os chamados Remédios de terra, estas pertenciam exclusivamente ao grupo popular: "Se estivesse em Cabo Verde... tanta gente que era mais velho, que sabia de tanta palha de erva que curava, já faleceu. Quase já não há remédio, palha de erva para fazer, já quando a gente sente sintoma de febre ou alguma coisa, já não está a fazer aquilo" (M, MJ, GP\}; "Cabo Verde com os mesmos problemas, é... pronto! Poderia ser mais complicado, porque recurso não é assim tão grande. Podia.... Aí éque 
eu poderia recorrer a outros meios, por exemplo, para evitar-me as dores, não sei quê. Podia recorrer a outros meios, porque lá em Cabo Verde não há essa gente..., faz sempre aquele medicamento da terra, não sei o quê, para evitar a dor, não sei o quê... Aí, muito bem" $\{\mathrm{H}, \mathrm{MV}$, $\mathrm{GP}$ \}. Isto torna-se contraditório, com relatos sobre práticas tradicionais, em que foram mencionados tratamentos que foram realizados sobretudo pelas pessoas do grupo de elite.

\section{Utilização e Acesso aos Serviços de}

\section{Saúde}

A diferença reconhecida entre os dois grupos sociais relativamente à utilização dos serviços de saúde encontra-se nos relatos sobre a utilização mais frequente dos serviços privados por parte dos indivíduos do grupo de elite, assim como o caso de pessoas que utilizam exclusivamente os serviços particulares, situação referida por duas mulheres deste grupo.

No que respeita a utilização dos serviços de urgência, os motivos são idênticos para todos os entrevistados: recorre-se numa situação de aflição, em alturas em que já não é possível encontrar o médico de família.

Não se observam diferenças significativas quando se abordam as dificuldades ou barreiras sentidas na utilização dos serviços de saúde, mas podemos, no entanto, verificar que são as pessoas do grupo de elite que mais evidenciam ter uma boa relação com o seu médico de família. Todos dizem que se sentem bem atendidos e, de um modo geral, que gostam dos seus médicos de família com quem mantêm uma boa relação.

Relativamente à relação com os profissionais de saúde encontrámos alguns casos em que o contato com os médicos foi negativo: "Eu senti que parece que... maneira de falar, tipo que ela é racista” $\{M, M V$, GP\}; "...Não gostei porque o médico foi muito estúpido e não gostei do tratamento e não confiei naquilo que ele tinha-me dito e acabei por ir para um médico particular. Aí mostrei o raio x que acabou por confirmar a fractura e disse que não valia a pena imobilizar porque isto tinha que ser nas primeiras 3 semanas e já tinha passado e só disse para ter cuidado" $\{\mathrm{M}, \mathrm{MJ}, \mathrm{GE}\}$. Al- guns entrevistados referiram que, de fato, quando chegaram a Portugal, sentiram algumas barreiras ou dificuldades, por desconhecimento do modo de funcionamento do sistema de saúde, mas que agora já se sentem perfeitamente adaptados: “Em princípio tinha dificuldades, a minha tia acompanhava-me sempre mas agora já conheço” $\{\mathrm{M}, \mathrm{MJ}, \mathrm{GP}\}$; “Antes tinha dificuldades porque eu desconhecia, não sentia à vontade. Estando cá e com uma criança e hospital faz parte ou quando ele cai ou tem que tomar vacinas... a pessoa vai-se habituando" $\{\mathrm{M}, \mathrm{MJ}, \mathrm{GE}\}$ e há pessoas que falam em dificuldades financeiras, dificuldades relacionadas com a falta de documentação e com as condições de trabalho. Apesar de não existir uma grande distância cultural, nem barreiras muito acentuadas entre esta comunidade e a do país de acolhimento, alguns indivíduos admitiram sentir limitações e dificuldades de acesso aos serviços de saúde. Tal como Loue afirma, podem existir no seio dos imigrantes barreiras economicas, mas também barreiras "não financeiras" (tais como a língua, transporte, cultura, mobilidade, falta de informação e fatores ocupacionais). Para além disso, e não sem menor importância, existem as barreiras legais e burocráticas (Loue, 1998).

Ao nível da análise por genero, as únicas diferenças encontradas residem em relatos de homens do grupo popular que dizem que não vão ao médico e no caso das mulheres de elite que preferem utilizar exclusivamente os serviços particulares de saúde.

No que diz respeito ao acesso aos serviços de saúde, verificamos nas entrevistas efetuadas, que a população estudada recorre preferencialmente aos Centros de Saúde e que tem médico de família. Comprova-se que "existe uma alteração de comportamentos após o processo migratório, através de uma maior frequência e uma maior utilização dos serviços de saúde convencionais, devido a uma melhor qualidade e uma maior acessibilidade aos serviços em Portugal» (França, 1992). Podemos considerar que não existem aparentemente grandes diferenças entre a forma como os cabo-verdianos se comportam comparativamente com a população portuguesa, com as mesmas características.

Através do no nosso estudo, verificamos a mesma situação que é descrita por Smaje (Smaje, 1995) 
sobre a utilização dos serviços de saúde, principalmente quando se trata do grupo popular. Observase que este utiliza com frequência os serviços de medicina geral, mas recorre pouco aos serviços externos de especialidade. Há um número elevado de pessoas entrevistadas que estão inscritas em médicos de família nos Centros de Saúde, mas que existem também muitos casos de indivíduos que recorrem simultaneamente aos serviços públicos e privados de saúde.

As escolhas terapêuticas traçam itinerários entre os vários recursos terapêuticos disponíveis na comunidade. Enquanto em Cabo Verde se utilizavam, com maior frequência, os vários recursos terapêuticos, em Portugal predomina o recurso ao Serviço Nacional de Saúde. As pessoas usam este sistema de forma convencional e recorrem geralmente em primeiro lugar, ao centro de saúde e só em situações de urgência extrema, é que recorrem às urgências hospitalares. Muitas vezes a primeira escolha é o Centro de Saúde, outras vezes são os cuidados ao domicílio, e ainda, por vezes, o especialista ou o sistema privado em geral. As idas ao médico servem para confirmar ou negar a hipótese diagnosticada através dos sintomas e para pedir o respectivo tratamento. 0 não fornecimento de uma explicação satisfatória ou um resultado pouco eficaz do tratamento da doença podem originar ou a já ter originado anteriormente a causa da ida do doente a um curioso, ou curandeiro, o que acontecia, no entanto, predominantemente em Cabo Verde. Ilustrativo a este respeito é o caso do senhor que relata "Quando o médico disse que não tinha solução eu tive de recorrer à cura tradicional, tinha 40 anos, fui a um senhor de S. Nicolau que deixou vários discípulos que tratam os ossos. Fazem um tratamento com água do mar aquecida e vinagre e fazem massagens na perna" $\{\mathrm{H}, \mathrm{MV}, \mathrm{GE}\}$.

Desta forma, apesar de recorrer ao médico frequentemente, sobretudo como um dos primeiros passos na resolução de um problema de saúde, o doente pode, ao mesmo tempo ou sequencialmente, recorrer aos especialistas da medicina tradicional como é o caso dos curiosos, espertos ou endireitas, ou ainda, a outro tipo de pessoas com capacidade para lidar com o problema que os aflige, não esquecendo as orações e promessas.

\section{Utilização de Remédios Caseiros - "Remédio de terra"}

A utilização de remédios caseiros como forma de prevenção - purgantes- para certas doenças foi essencialmente referida por indivíduos do grupo de elite. Na sua generalidade, porém, todos os indivíduos foram tratados, numa ou outra situação, com remédios caseiros para tratar doenças da infância e quase todos são de opinião que estes tratamentos são eficazes. No entanto, todos eles afirmam que isso não representava uma forma de substituição das consultas no posto de saúde ou no hospital, já que esta situação se aplicava somente a um determinado tipo de doenças próprias das crianças ou doenças ligeiras, como dores de estômago, problemas digestivos, febre, gripes, tosses ou mesmo a bronquite asmática, que se prestavam a ser tratadas em casa com base nesses produtos. Recorria-se de imediato à medicina convencional quando as situações se complicavam. Hoje em dia, quase ninguém continua a tratar-se desta mesma forma, dado que, segundo dizem, não encontram cá os produtos requeridos, as chamadas ervas ou palhas usadas para fazer os chás, xaropes, óleos ou banhos, apesar de se manter o hábito de utilização deste tipo de infusões de louro, alho, casca de cebola, arruda, alecrim (para tratar perturbações de saúde provocadas pelo colesterol, pela hipertensão arterial, para a digestão ou para a febre), mesmo se o uso de produtos de ervanário ainda seja bastante frequente. Estes processos terapêuticos, que fazem parte de um conjunto de fatores culturais provenientes do país de origem, manifestam-se e ainda se mantêm presentes, pelo menos ao nível das histórias e das memórias descritivas, no conjunto das práticas da maioria dos indivíduos entrevistados. Existem reações diversas relativamente às terapias referidas embora sejam mais as pessoas que dizem que já as experimentaram e que as mães lhes davam estes remédios em criança, acreditando que ajudam a melhorar da doença, do que aquelas que negam acreditar nos chamados remédios de casa.

Algumas pessoas explicam que existe uma distinção entre o que é considerado doença de médico e aquela que não é de médico. Distinguem doenças que se vêem e doenças que não se vêem. Há ainda 
quem tente explicar as razões de antigamente se recorrer mais aos remédios caseiros do que nos dias de hoje, alegando que isto acontece porque são os mais velhos que detêm mais conhecimentos sobre estas práticas, ou ainda porque dantes não havia muitos médicos nem outros recursos nas ilhas e essa era uma forma de complementar a escassez de meios existentes.

\section{Outros Recursos e Terapias Alternativas}

Enquanto a maioria dos inquiridos já utilizou e tem uma opinião positiva sobre os remédios de terra, já são poucos os que dizem acreditar nos tratamentos feitos por curandeiros, ou ainda pelos chamados curiosos, em Cabo Verde. Dizem que não acreditam na eficácia das terapias efetuadas por estas pessoas, em quem não confiam pois, segundo eles, tentam desta forma roubar o dinheiro dos doentes. Alguns também se queixam de que até sentem receio e certa apreensão em relação a estas pessoas. No entanto, não deixam de admitir a existência desta prática, embora já não se encontre com tanta frequência como antigamente. Aqueles que reconhecem já ter usado essas terapias pertencem em número majoritário ao grupo de elite. A procura destes terapeutas não médicos é, muitas vezes, justificada pela ausência de médicos próximos das áreas onde as pessoas se encontravam. Há ainda quem fale acerca de parteiras, endireitas e pessoas espertas quando se referem a casos relacionados com terapeutas não médicos. Quem acredita nestes terapeutas é porque ele próprio também já recorreu a estas terapias, ou porque conhece alguém que o fez. Fundamentalmente recorre-se a pessoas com conhecimentos sobre tratamentos alternativos, semelhantes aos dos tratamentos caseiros, só depois de se ter tentado a medicina convencional. Alguns indivíduos mais velhos, todos do grupo de elite, relatam histórias em que eles próprios, recorreram a indivíduos da terra que faziam tratamentos alternativos: “...porque quando o médico por exemplo não conseguia pôr-me a andar..., o médico quase que não tinha solução. Eu tive que recorrer-me à cura tradicional. Mas nessa altura, já homem (quarenta anos, não é?) fui com a irmã à pessoa tradicional, e tive que arranjar um senhor, já que... (posso entrar em pormenores?)...um senhor de $S$. Nicolau, onde as pessoas... havia um famoso homem, antigo, que deixou vários discípulos que conseguem tratar os ossos...então o homem com a água do mar, água salgada, com vinagre e com o chamado «confortativo", que é um tipo de adesivo que tem um material... (não sei, era importado), durante dias a fio o homem ia a minha casa e fazia-me essas massagens...eu fiquei um pouco pensativo a principio porque ia contrariar [....] nas orientações do médico, mas eu ouvi que também se não fizesse algo mais talvez ficasse naquela situação de andar com muletas, com canadianas...." $\{\mathrm{H}, \mathrm{MV}, \mathrm{GE}\}$.

Como na análise efetuada por Sundquist (Sundquist, 1995) até certo nível social, os fatores socioeconomicos são decisivos relativamente à saúde nas suas diversas dimensões, mas ultrapassando esse nível, ou seja, nas classes de renda mais elevada, as diferenças de práticas de saúde dependem, sobretudo, de escolhas individuais condicionadas por fatores culturais. Exemplo disto é o recurso à homeopatia ou à acupuntura.

Relativamente a casos relacionados com feiticeiros, maus-olhados ou bruxaria, a maior parte dos entrevistados diz que não acredita nisso, ou que não conhece pessoalmente nenhuma história relacionada, independentemente do grupo social a que pertence. As pessoas não negam que já ouviram falar nessas situações, mas afirmam que não acreditam. Associam estas práticas a fazer mal aos outros e à inveja. Algumas pessoas do grupo popular associam os curandeiros aos feiticeiros, ao mau-olhado ou à bruxaria, e são estas que mais dizem não acreditar e ter medo ou receio. Também no grupo popular, a maior parte dos indivíduos mais velhos nunca utilizou, nem acredita neste tipo de terapeutas. Algumas pessoas do grupo popular, dizem que não acreditam nestas questões de doenças postas pelo "mal" e dizem que a sua fé é em Cristo, em Deus e na Nossa Senhora de Fátima, com a qual se identificam e que, se adoecerem, é a ela que recorrem, assim como ao médico e nunca a práticas ligadas a feiticeiros ou bruxas.

Pode-se dizer que as práticas religiosas e a fé fazem parte da educação cristã dos inquiridos e estão presentes em todos os discursos, já que, quase todos eles afirmam ser católicos ou, no caso 
de algumas pessoas do grupo de elite, professam a religião protestante. Apesar disso, a prática de pedir a intervenção divina em caso de doença não é muito frequente, talvez porque, conforme foi referido pelos entrevistados, ainda não sentiram essa necessidade. No caso das pessoas que afirmaram recorrer à Nossa Senhora de Fátima, estas fazem parte do grupo popular e algumas contam que visitaram o Santuário onde foram pagar promessas relacionadas com doenças ou operações. Entre os entrevistados, existem pessoas cujos percursos pessoais, profissionais e familiares estão ligados à igreja, sendo a fé inerente às suas práticas quotidianas, incluindo, obviamente, a saúde e a doença.

Outro fenomeno específico que existe em Cabo Verde, sobretudo na ilha de São Vicente, e que é predominante no seio da elite intelectual é o chamado espiritismo, como já tivemos ocasião de abordar na discussão teórica, relacionado com o racionalismo cristão (Vasconcelos, 2001).

\section{Conclusão}

Consideramos, de um modo geral, se tratar de uma população saudável, com comportamentos salutares e práticas viradas para um estilo de vida saudável, que provêm da cultura de origem, bem como dos contextos socioeconomicos. Encontramos, em termos de cuidados com a saúde e práticas de prevenção, uma diferença entre os dois grupos sociais, sendo particular ao grupo de elite o hábito de fazer análises e check-ups de rotina como forma de prevenção. No livro "The Black Report" (Towsend e Black, 1992), uma das razões identificadas para a existência de diferenças de saúde é a explicação comportamental e cultural, que envolve diferenças de classe social em comportamentos que são destrutivos ou são promotores da saúde e que, em princípio, dependem de escolhas individuais. As preferências alimentares, o consumo de drogas, o tabaco e álcool, as actividades de tempos livres e o uso dos serviços de medicina preventiva, como a imunização, contracepção e observação pré-natal são exemplos de comportamentos que variam em função do grupo social e que podem contribuir para as diferenças de classe na saúde. As dietas ou hábitos alimentares são influenciados tanto por preferências culturais, como pelas disponibilidades financeiras. De acordo com Loue, os imigrantes trazem com eles sistemas de crenças e práticas de saúde dos seus países com heranças e experiências culturais próprias (Loue, 1998). Essas práticas podem manter-se ativas por vezes durante várias gerações. Todos os recursos a que se recorre no tratamento e cura são produto de culturas e correspondem a práticas preventivas e ações terapêuticas comuns nas tradições culturais. O uso simultâneo das medicinas tradicional e "moderna" coexiste e um sistema não substitui o outro. Partimos da ideia de que não existe uma correlação entre uma utilização continuada do sistema tradicional e o nível de utilização dos serviços modernos, nem uma correlação com um nível mais elevado de aculturação na cultura de acolhimento.

Os indivíduos que fazem parte do estudo experimentaram, ao nível das suas práticas, os três sistemas de saúde que coexistiam em Cabo Verde, nomeadamente, o oficial, o popular e o tradicional/ alternativo, e ainda o recurso à religião. As pessoas podem recorrer a estes sistemas de formas diversas, quer usando um só ou mais do que um, de modo simultâneo ou sequencial, conforme as necessidades sentidas pelo indivíduo quando se encontra em situação de doença. Kleinman (Kleinman, 1984) defende que, após a análise de qualquer sociedade complexa, é possível identificar três sistemas básicos de assistência à saúde: o oficial ou profissional, o popular e o informal ou tradicional. O oficial engloba o sistema nacional de saúde, tem enquadramento legal, envolve tecnologias, a formação dos profissionais de saúde e baseia-se na medicamentação de "farmácia". O setor popular inclui curandeiros, o poder da cura, o tratamento de doenças causadas por feitiçarias ou punição divina e recorre à auto-medicação, ervanários, ervas medicinais. Este sistema está mais próximo da população, com padrões culturais semelhantes. Quanto ao sistema informal, este tem a ver com o recurso a leigos em caso de doença, recurso à auto medicação e à família, onde a mulher tem um papel fundamental.

Podemos considerar também que, em termos de modelos de tratamento, encontramos a medicina oficial, o remédio de terra e o tratamento espiritual. Como exemplo de remédio de terra, é referido um curandeiro em Santo Antão que possui poderes de 
diagnóstico e cura e o fato deste apenas praticar o "bem" através de atos de cura e não de feitiçaria. Quanto ao modelo de tratamento espiritual, em Cabo Verde o espiritismo é fundamentalmente representado pelo racionalismo cristão, sendo que a incorporação de espíritos, chamada de "manifestação", produz frequentemente diagnósticos espirituais, nos quais feitiços, maus-olhados ou a influência dos "espíritos inferiores", são revelados. Berta Nunes (Nunes, 1997) distingue cinco tipos de recursos terapêuticos: os auto cuidados (família, vizinhos), as terapias parciais (endireitas) ${ }^{5}$, os sábios (tratam as doenças causadas por almas de defuntos e outras causas sociais da doenças: o mal de inveja, mau olhado), os santos particulares (protegem contra a doença e a má sorte, curam doenças e ajudam a resolver problemas), e, por fim, os centros de saúde e hospital. Este último recurso terapêutico faz parte do modelo biomédico da doença, onde não são tidos em conta os seus aspectos culturais e sociais. $\mathrm{O}$ modelo bio psico social, por outro lado, pressupõe a integração dos fatores psicológicos e sociais na abordagem da pessoa doente e da sua doença. Vários autores têm ainda proposto a inclusão de fatores culturais, como é o caso do modelo bio psico sócio cultural de abordagem da doença e do doente. Encontramos também estes cinco tipos de recursos terapêuticos. É importante reconhecer a existência de uma pluralidade terapêutica na mesma unidade sócio cultural. As pessoas usam os vários setores em paralelo e simultaneamente, mas, muitas vezes, para propósitos diferentes. Sempre houve contacto entre as duas medicinas, entre a cultura erudita e «sábia» e uma cultura popular. É no espaço de impotência e incompetência da medicina "sábia" que se alastraram as medicinas paralelas (Loux, 1983). Geralmente, em países predominantemente rurais, este sistema tradicional existe e é muito usado, providenciando um sistema de saúde complementar muitas vezes mais acessível do que o sistema biomédico, o setor profissional. o que caracteriza a medicina tradicional e popular, para além do contato e da proximidade física daquele que trata num quadro familiar e o aspecto globalizante da percepção da doença e da terapia, é sobretudo a relação estreita da questão do "como" etiológico e terapêutico com uma "interrogação sobre o porquê" reportado à subjetividade do doente.

Os remédios tradicionais têm um significado próprio para alguns grupos da população minoritária e o seu uso pode ser conceptualizado como um recurso adicional que é utilizado como um complemento ou substituto dos remédios receitados. Para outros, pode constituir apenas um tonico para revitalizar e limpar o sistema. Podem, também, estar associados à continuação da crença nos sistemas alternativos de saúde e ao significado da percepção que têm as minorias relativamente aos tratamentos ocidentais. Como vemos, há diferenças intra e inter-étnicas que estão relacionadas não só com a cultura, mas também com a geração e a posição socioeconomica em que as pessoas se situam. Verifica-se, também, que as pessoas pertencentes às classes de renda mais alta na sociedade de acolhimento, começaram a adoptar as terapias tradicionais, sobretudo entre as gerações mais novas. 0 grau de aceitação da medicina moderna difere entre os diferentes grupos sociais e entre as minorias étnicas. Entre as minorias étnicas há uma associação entre a sua auto-identidade ou sentimento de pertença a uma comunidade, com a terra de origem e a permanência de aspectos de uma cultura distinta em termos das suas instituições sociais (religião, estrutura familiar e casamento), normas sociais, maneiras, atitudes, modo de pensar e comportamentos sociais (alimentação, vestuário, práticas de saúde). 0 estudo de Gomes (1999) acrescenta que a identidade caboverdiana é ambígua, pois simultaneamente adopta e resiste às suas origens africanas e europeias, o que revela a existência de um elemento de escolha na construção social da identidade. À medida que se vai subindo na pirâmide social, a identidade étnica vai enfraquecendo, o que neste estudo não parece até agora ser aplicável.

Todo e qualquer sistema de saúde possui dois aspectos inter-relacionados, o aspecto cultural e o aspecto social. As sociedades modernas, complexas e industrializadas têm sistemas pluralistas de cuidados de saúde, contendo geralmente em simultâneo um subsistema popular (sistema não

5 Indivíduo que conserta os ossos fraturados ou em luxação, também vulgarmente conhecido por algebrista. 
médico relacionado com opções dos próprios indivíduos, auto-medicação, conselhos e orientações da família), um subsistema tradicional (medicina popular, curandeiros) e o subsistema profissional (sistema de saúde ocidental). Os indivíduos optam por uns ou/e por outros, consoante as situações (Laplantine, 1992).

Em contexto migratório, um dos indicadores de integração cultural no campo da saúde e o grau de medicalização, é o uso de remédios tradicionais, ervas e a utilização de tratamentos ocidentais (Williams, 1996). Verifica-se, na prática, a participação num sistema dual de cuidados de saúde, em que são utilizadas as duas formas de tratamento. Parece correto afirmar que os mais velhos continuam a adotar estas práticas, enquanto os mais novos rejeitam parcialmente esta tradição. A mudança intergeracional é comum no caso dos filhos dos imigrantes submetidos a um processo de "aculturação/medicalização", enquanto aspecto de adopção geral de crenças, práticas e estilos de vida da cultura "dominante".

Tendo como referência o nosso objeto de estudo, podemos concluir que a comunidade cabo-verdiana residente em Portugal parece ser uma população saudável, cujos problemas de saúde não são muito diferentes daqueles de que padece a população portuguesa em condições socioeconomicas semelhantes.

São os fatores socioeconomicos que determinam a relação com a saúde e não outra ordem de fatores (Smaje, 1995). Segundo Sarah Nettleton, podem ser identificadas explicações para padronizar o estado de saúde pela etnicidade, através de fatores genéticos, culturais e socioestruturais. Sem excluir que os dois primeiros fatores podem ter alguma influência, a evidência sugere que as circunstâncias sociais nas quais as pessoas vivem e a natureza das relações sociais que os indivíduos "experimentam" são as considerações mais importantes. As questões culturais, pelo seu lado, explicam diferenças na saúde em termos de comportamentos e estilos de vida (Nettleton, 1995).

O discurso analisado acerca das práticas de saúde e de doença demonstrou existirem diferenças, em alguns aspectos, entre os grupos sociais. Foram en- contradas também ligeiras diferenças nas práticas entre os generos e as gerações. Podemos concordar com Saint-Maurice (Saint-Maurice, 1997) quando diz que, o grupo dominante, neste caso, o grupo de elite, ao nível simbólico e em determinadas circunstâncias salienta a sua identidade étnica, mas, em termos de modos de vida, em sentido estrito, evidencia a sua identidade socioeconomica. Salienta que, no caso dos dominantes (elite) cabo-verdianos, ao nível simbólico, reforçam a sua etnicidade, valorizando-a como positiva e orgulhosamente, ao mesmo tempo que, ao nível comportamental, se aproximavam da classe dominante da sociedade receptora. Já no caso dos cabo-verdianos com condições socioeconomicas desfavorecidas, estamos perante um processo de diferenciação quer ao nível das representações e dos comportamentos, relegando-os para uma situação de exclusão social, acrescenta a autora. Esta autora conclui que se tratam de duas "ethclass" específicas em que existe uma contribuição tanto do grupo social como da identidade étnica. Estes dois fatores funcionam simultaneamente e, se não são determinantes, pelo menos orientam as práticas e os comportamentos de saúde e de doença.

As práticas de saúde destes imigrantes são idênticas às dos portugueses que se encontram em contextos socioeconomicos semelhantes, não havendo um impacto significativo da migração nessas práticas.

\section{Referências}

BÄCKSTRÖM, B. et al. Imigração e saúde: o gabinete de saúde do CNAI enquanto observatório para o estudo das condições de acesso dos imigrantes aos serviços de saúde. Revista Migrações, Lisboa, n.4, p. 161-189, 2oogb.

BARDIN, L. Análise de conteúdo. Lisboa: Edições 70, 2007. (Extra Colecção).

DONOVAN, J. L. Ethnicity and health: a research review. Social Science and Medicine, Oxford, v. 19, n. 7, p. 663-670, 1984.

FRANÇA, L. (org.). A comunidade Cabo Verdiana em Portugal, Lisboa: Instituto de Estudos para o desenvolvimento, 1992. (Caderno 23). 
FONSECA, L. (org.) Mighealthnet: rede de informação sobre boas práticas em cuidados de saúde para imigrantes e minorias étnicas na Europa - Relatório sobre o Estado da Arte em Portugal. Lisboa: Centro de Estudos Geográficos; Universidade de Lisboa, 2009.

GERMOV, J. Second opinion: an introduction to health sociology. Melbourne, New York: Oxford University Press, 1998.

GOMES, I. B. (org.) Estudo de caracterização da comunidade cabo-verdiana residente em Portugal. Lisboa: Embaixada de Cabo Verde em Portugal, 1999 .

GUERRA, I. C. Pesquisa qualitativa e análise de conteúdo, Estoril: Principia, 2006.

KLEINMAN, A. Patients and healers in the context of culture: an exploration of the borderland between anthropology, medicine and psychiatry. Berkley: University of California Press, 1984.

LAPLANTINE, F. Anthropologie de la maladie: étude ethnologique des systèmes de représentations étiologiques et thérapeutiques dans la société occidentale contemporaine. Paris : Payot, 1992.

LOUX, F. Traditions et soins d'aujord'hui. Paris: InterEditions, 1983.

LOUE, S. (org.) Handbook of immigrant health. New York: Plenum Press, 1998.

MANUEL, H. B. Conhecimentos, atitudes e práticas sobre planeamento familiar de mulheres timorenses residentes em Portugal. Lisboa: Observatório da Imigração; Alto Comissariado para a Imigração e Diálogo Intercultural, 2007. (Teses, 8).

MONTEIRO, I. Ser mãe Hindu: práticas e rituais relativos à maternidade e aos cuidados à criança na cultura Hindu em contexto de imigração. Lisboa: Observatório da Imigração; Alto Comissariado para a Imigração e Diálogo Intercultural, 2007. (Teses, 9).

NETTLETON, S. The sociology of health and illness. New York: Polity Press, 1995.
NUNES, B. O saber médico do povo. Lisboa: Editora Fim de século, 1997.

RODRIGUES, N. M. L. "Doença da terra" $e$ "doença da farmácia”: um estudo da relação entre a medicina popular e a medicina oficial em Cabo Verde, uma sociedade em mudança. 1991. Dissertação (Mestrado em Antropologia Social) - Departamento de Antropologia, Faculdade de Filosofia, Letras e Ciências Humanas da Universidade de São Paulo, São Paulo, 1991.

SAINT-MAURICE, A. Identidades reconstruídas: cabo-verdianos em Portugal. Lisboa: Celta, 1997.

SMAJE, C. Health "Race" and ethnicity: making sense of the evidence. London: Kings Fund Institute, 1995 .

SOUSA, J. E. Os imigrantes ucranianos em Portugal e os cuidados de saúde. Lisboa: Observatório da Imigração; Alto Comissariado para a Imigração e Diálogo Intercultural, 2006. (Teses, 4).

SUNDQUIST, J. Ethnicity, social class and health. A population-based study on the influence of social factors on self-reported illness in 223 Latin American refugees, 333 Finnish and 126 south European labour migrants and 841 Swedish controls. Social Science and Medicine, Oxford, v. 40, n. 6, p. 777-787, mar. 1995.

TOWSEND, P.; BLACK, D. Inequalities in health: the black report. London: Penguin, 1992.

VACONCELOS, J. Espíritos lusófonos numa ilha crioula: língua, poder e identidade em São Vicente de Cabo Verde. Lisboa: Imprensa de Ciências Sociais, 2001.

UNIKEN VENEMA, H. P.; GARRETSEN, H. F. L; VAN DER MASS, P. J. Health of migrants and migrant health policy, the Netherlands as an example. Social Science and Medicine, Oxford, v. 41, n. 6, p. 8o9-818, sept. 1995.

WILLIAMS, D. R.; RUCKER, T. Socioeconomic status and the health of racial minority populations. In: KATO, P. M.; MARUR, T. The plenum series in culture and health. Handbook of diversity issues in health psychology. New York; London: Plenum Press, 1996. 
WILLIAMS, S. J.; CALNAN, M. Modern medicine:

lay perspectives and experiences. London: UCL

Press, 1996.

Recebido em: 20/05/2010

Reapresentado em: 14/03/2011

Aprovado em: 10/05/2011 